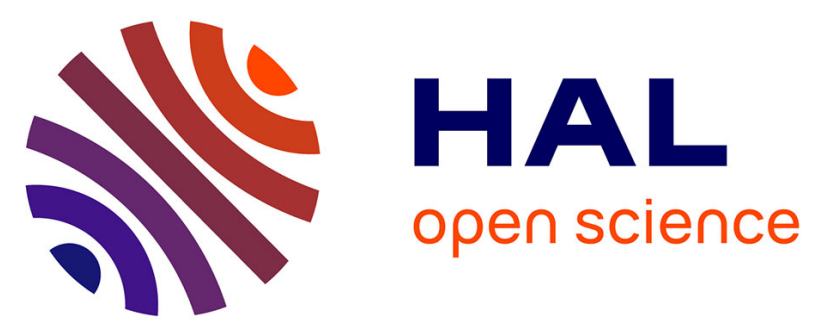

\title{
3-D Generic Magnetic Equivalent Circuit Taking Into Account Skin Effect: Magnetic Field and Eddy-Current Losses
}

Youcef Benmessaoud, Walid Belguerras, Frédéric Dubas, Mickaël Hilairet

\section{- To cite this version:}

Youcef Benmessaoud, Walid Belguerras, Frédéric Dubas, Mickaël Hilairet. 3-D Generic Magnetic Equivalent Circuit Taking Into Account Skin Effect: Magnetic Field and Eddy-Current Losses. ELECTRIMACS, May 2019, Salerno, Italy. hal-02299910

\section{HAL Id: hal-02299910 https://hal.science/hal-02299910}

Submitted on 28 Sep 2019

HAL is a multi-disciplinary open access archive for the deposit and dissemination of scientific research documents, whether they are published or not. The documents may come from teaching and research institutions in France or abroad, or from public or private research centers.
L'archive ouverte pluridisciplinaire HAL, est destinée au dépôt et à la diffusion de documents scientifiques de niveau recherche, publiés ou non, émanant des établissements d'enseignement et de recherche français ou étrangers, des laboratoires publics ou privés. 


\title{
3-D Generic Magnetic Equivalent Circuit Taking Into Account Skin Effect: Magnetic Field and Eddy-Current Losses
}

\author{
Youcef Benmessaoud Walid Belguerras Frédéric Dubas Mickael Hilairet
}

\begin{abstract}
In this paper, a three-dimensional (3-D) generic magnetic equivalent circuit (MEC) in Cartesian coordinates considering the skin effect is developed. This model has been applied to a U-cored static electromagnetic device. The main objective is to compute the magnetic field behaviour in massive conductive parts (viz., aluminium) and to predict the impact of the eddy-current magnetic fields in the neighbouring non-conductive parts. The classical magnetomotive force (MMF) distribution has been modified by integrating the MMF produced by the eddy-currents that occur in massive conductive regions. The eddy-current MMF was introduced by formula which derived from magnetodynamic Maxwell's equations. Both Experimental tests and three-dimensional (3-D) finite-element analysis (FEA) have been used to prove the validity of the proposed approach.
\end{abstract}

\section{Introduction}

\subsection{Context of this paper}

Different models more or less accurate, taking into account spatio-temporal harmonics have been developed in the past. The importance of studying the eddy-currents topic still remains attractive in static or/and dynamic applications such as non-destructive control, permanent-magnet (PM) synchronous machines (PMSMs). Indeed, incorporating PMs in electrical machines improve really the efficiency and the behaviour of the integral quantities. However, the presence of

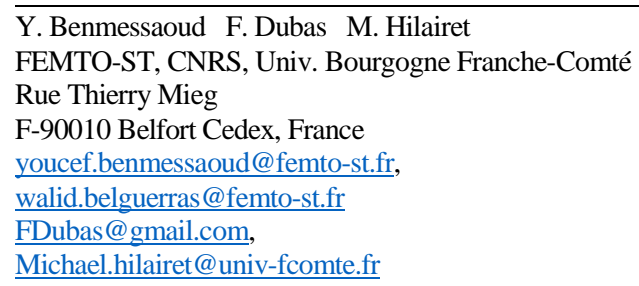

conductive materials can consist a technical drawback in the high frequency, causing additional losses at high-speed which dissipate in the heat forms, leading to the PMs degradation. Indeed, the magnetic field variation is one of the main source of these losses which further affect the electromagnetic proprieties. This meant that eddy-currents become essential when sizing PMSMs at high-speed.

In order to estimate these eddy-current losses, different modeling technics in the literature can be found based on different formulations [1]. It can be find analytical models based on the formal resolution of Maxwell's equations [2], the finite-difference method from Maxwell's equations where the boundary conditions (BCs) come from the FEA [3], the hybrid models [4],..., the semi-analytical model based on the MEC (or reluctances network). Different manner to incorporate magnetic reluctances, magnetic inductances or MMFs in MEC or coupling models with MEC to compute eddy-currents [5-8]. The main drawbacks of the last works can be liked to the incorporated MMFs or magnetic reluctances which don't take into account the skin effect as well as the method depend on the FEA to get the local quantities that allows computing eddy-current losses. Add to this, no model exist till now which permit to study the skin effect on the behaviour of the magnetic field overs all the electromagnetic devices by applying only the MEC.

\subsection{Objectives of this paper}

In this paper, a new approach is proposed to incorporate the MMFs which take into account the skin effect in the semianalytical model based on the 3-D generic MEC. In this way, it can be analysed the impact of the magnetic fields due to eddy-currents occurred in massive conductive parts and over all parts of the electromagnetic devices. The performed model will be able to compute the eddy-current losses in massive conductive parts, to predict the behaviour of both magnetic field and flux density over all the electromagnetic device. The 
segmentation in the two axes is also allowed but not treated in this paper.

\section{U-cored static electromagnetic device}

Fig. 1 shows the two-dimensional (2-D) view of the static electromagnetic device whose the experimental tests have been presented in [9]. This device is constituted by a mobile armature that allows to insert massive conductive parts (viz., aluminium) of various thicknesses. Two coils having $N_{t}$ serie turns are connected in parallel. It is supplied with a sinusoidal voltage. Since the magnetic circuit is not saturated, the current is then sinusoidal waveform with a maximum amplitude of $I_{\max }$. The geometric and physics parameters are given in Tab. 1

\section{3-D generic MEC using mesh-based formulation}

The 3-D automatic generation MEC using mesh-based formulation is already developed and explained in [10]. This provides the distributions of magnetic flux density $\boldsymbol{B}=\left\{B_{x} ; B_{y} ; B_{z}\right\}$ in all parts of an electromagnetic device. In [10], the MMF associated to massive conductive parts are equal to zero because the skin effect has been neglected. The results of $\boldsymbol{B}$ were confronted with those obtained by the 3-D FEA. The computation time is divided by 3 with an error less than $1 \%$. In the following section, it is explained the followed approach to associate the MMFs produced by the magnetic reaction field taking into account eddy-current phenomenon.

\section{Developed approach}

\subsection{Principle of model}

Fig. 2 represents the flowchart that explains the approach followed to incorporate the MMF produced by the eddycurrents in massive conductive parts into the 3-D generic MEC. Firstly, it is not considered the electrical conductivity of the massive conductive parts. Hence, the 3-D generic MEC results correspond to those levied at magnetostatic application. Next, the magnetic flux density in the middle of the massive conductive part will be considered to define the BCs to resolve the complex Helmholtz's equation. At this stage, the evolution of the eddy-current magnetic field can be got. Thereafter, Hopkinson's law will be applied to estimate the MMFs due to the magnetic field reaction caused by the massive conductive parts. Finally, these later will be incorporated into the performed 3-D generic MEC. New simulation gives the results by considering the electrical conductivity of the massive parts. Furthermore, it can be remarked that the crossing flux tube in the electromagnetic device when considering the electrical conductivity can be affected in values and length terms.

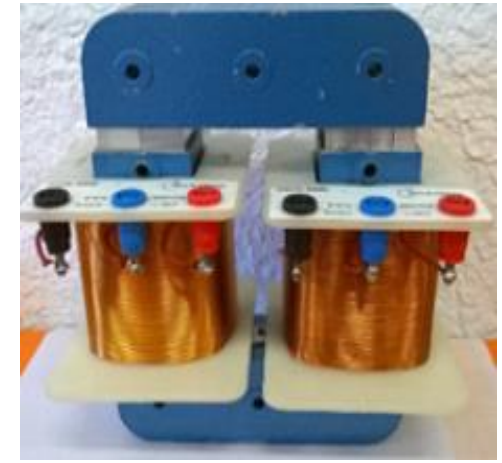

(a)

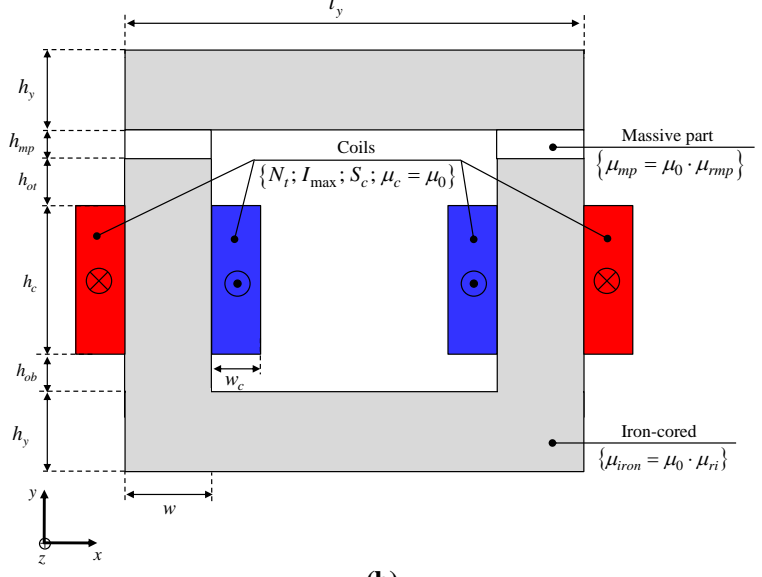

(b)

Fig. 1 U-cored static electromagnetic device: (a) Experimental test [9], and (b) Geometrical parameters.

Table 1 Geometrical and physical parameters

\begin{tabular}{cc}
\hline \hline Parameter, Symbol [Unit] & Value \\
\hline \hline Depth, $d[\mathrm{~mm}]$ & 43 \\
\hline Width, $w[\mathrm{~mm}]$ & 43 \\
\hline Coil height, $h_{c}[\mathrm{~mm}]$ & 77 \\
\hline Coil width, $w_{c}[\mathrm{~mm}]$ & 10 \\
\hline Coil section, $S_{c}=h_{c} \cdot w_{c}\left[\mathrm{~mm}^{2}\right]$ & 770 \\
\hline Yoke height, $h_{y}[\mathrm{~mm}]$ & 43 \\
\hline Yoke length, $l_{y}[\mathrm{~mm}]$ & 150 \\
\hline Thickness of massive part, $h_{m p}[\mathrm{~mm}]$ & 6 or 10 \\
\hline Height overhang top, $h_{o t}[\mathrm{~mm}]$ & 19 \\
\hline Height overhang bot, $h_{o b}[\mathrm{~mm}]$ & 4 \\
\hline Electrical frequency, $f[\mathrm{~Hz}]$ & 50 or 1,600 \\
\hline Maximal current, $I_{\text {max }}[\mathrm{A}]$ & 0 to 8.2 \\
\hline Number of turns, $N_{t}[-]$ & 500 \\
\hline Relative permeability of massive parts in \\
aluminium, $\mu_{r m p}[-]$
\end{tabular}




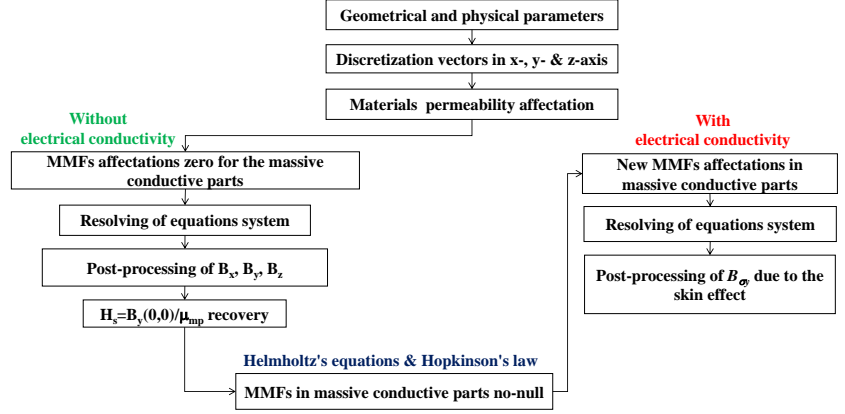

Fig. 2 Flowchart of 3-D generic MEC with the skin effect.

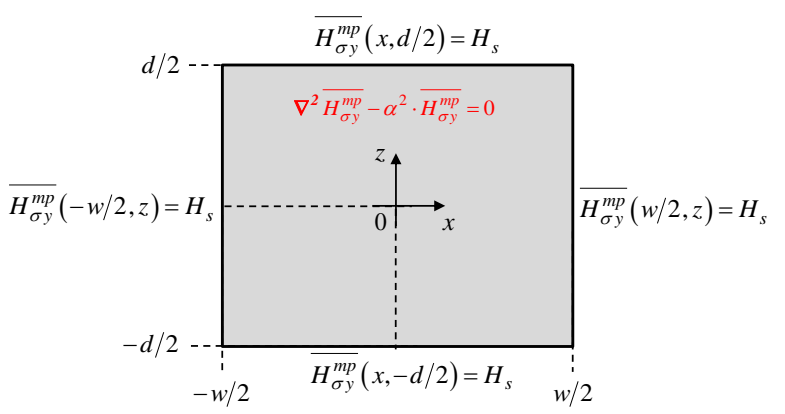

Fig. 3 BCs at edges of massive conductive parts in $(x, z)$ coordinate system.

\subsection{Magnetic field due to electrical conductivity in massive conductive parts}

To estimate the MMFs with the skin effect wherever in the massive conductive part, the approach derived from the formal resolution of Maxwell's equations by using the separation of variables method and the Fourier's series. In quasi-stationary approximation, inside a linear (non)magnetic material of electrical conductivity without electromagnetic sources, the partial differential equation in magnetodynamic in term of $\boldsymbol{H}^{m p}$ can be defined by [1]

$$
\nabla^{2} \boldsymbol{H}^{m p}-\mu \cdot \sigma \cdot \frac{\partial \boldsymbol{H}^{m p}}{\partial t}=0 \text { (Diffusion equation) }
$$

In Cartesian coordinates $(x, z), \boldsymbol{H}^{m p}=\left\{0 ; H_{\sigma y}^{m p} ; 0\right\}$ with $H_{\sigma y}^{m p}=\mathfrak{R}\left\{\overline{H_{\sigma y}^{m p}} \cdot e^{\mathbf{j} \cdot \omega \cdot t}\right\}$, where $\mathbf{j}=\sqrt{-1}$ and $\omega=2 \pi \cdot f$ is the electrical pulse, in massive conductive parts considering the skin effect is then governed by the complex Helmholtz's equation, viz.,

$$
\frac{\partial^{2} \overline{H_{\sigma y}^{m p}}}{\partial x^{2}}+\frac{\partial^{2} \overline{H_{\sigma y}^{m p}}}{\partial z^{2}}-\alpha^{2} \cdot \overline{H_{\sigma y}^{m p}}=0
$$

where $\alpha^{2}=\mathbf{j} \cdot \mu_{m p} \cdot \sigma_{m p} \cdot \omega$.

The BCs are considered homogeneous at the edges of massive conductive parts, which are equal to $H_{s}$. This value of magnetic field is defined as the normal magnetic field value crossing the middle of the massive conductive part determined by magnetostatic 3-D generic MEC i.e., without electrical conductivity, viz., $H_{s}=B_{y}(0,0) / \mu_{m p}$. The various BCs are shown in Fig. 3.

By using the separation of variables method and by applying the BCs, the 2-D general solution of $H_{\sigma y}$ in both directions (i.e., X- and z-edges) can be written as Fourier's series [1]

$$
\begin{aligned}
& \overline{H_{\sigma y}^{m p}}=H_{s} \cdot \overline{f_{\sigma}(x, z)}, \\
& \overline{f_{\sigma}(x, z)}=\left\{\begin{array}{l}
\frac{\operatorname{ch}(\alpha \cdot z)}{\operatorname{ch}\left(\alpha \cdot \frac{d}{2}\right)} \\
\cdots+\sum_{k=1,3, \ldots}^{\infty} \overline{e_{k}^{z}} \cdot \operatorname{ch}\left(\delta_{k} \cdot x\right) \cdot \cos \left(\lambda_{k} \cdot z\right)
\end{array}\right\}, \\
& \overline{e_{k}^{z}}=2 \cdot\left[1-\left(\frac{\lambda_{k}}{\delta_{k}}\right)^{2}\right] \cdot \frac{\operatorname{sinc}\left(\lambda_{k} \cdot \frac{d}{2}\right)}{\operatorname{ch}\left(\delta_{k} \cdot \frac{w}{2}\right)},
\end{aligned}
$$

where $\lambda_{k}=k \pi / d$ is the periodicity of $\overline{H_{\sigma y}^{m p}}$ in the z-axis, $\delta_{k}=\sqrt{\alpha^{2}+\lambda_{k}^{2}}, k$ are the spatial harmonic orders.

It should be noted that $H_{\sigma y}^{m p}$ is assumed to be invariant in the y-axis. Moreover, when $\alpha=0$ (viz., $\sigma_{m p}=0 \mathrm{~S} / \mathrm{m}$ and/or $f \cong 0^{+} \mathrm{Hz}$ ) then $\overline{f_{\sigma}(x, z)}=1$ thus giving $\overline{H_{\sigma y}^{m p}}=H_{s}$.

\subsection{Hopkinson's law to estimate the MMF values with the skin effect}

As it is explained in the sections before, initially the MMFs associated to massive conductive parts are equal to zero. In reality, the magnetic field inside and outside the massive conductive parts is affected by electrical conductivity. Therefore, the MMFs in the massive conductive parts can not be equal to zero. To estimate the eddy-currents MMFs that occur in massive conductive parts, the Hopkinson's law on a "flux tube" in massive conductive parts is used as well as (3). . So the eddy-currents MMFs are defined by

$$
\begin{aligned}
& \overline{M M F_{\sigma}^{m p}(x, y)}=H_{s} \cdot \frac{h_{m p}}{2 \cdot N d_{3}^{y}} \cdot\left[1-\overline{f_{\sigma}(x, z)}\right], \\
& M M F_{\sigma}^{m p}=\mathfrak{R}\left\{\overline{M M F_{\sigma}^{m p}} \cdot e^{\mathbf{j} \cdot \omega \cdot t}\right\} .
\end{aligned}
$$

Finally, $M M F_{\sigma}^{m p}$ will be incorporated into the 3-D generic MEC in massive conductive parts by respecting the discretization number in the $y$-axis chosen in the massive 
piece zone, viz., $N d_{3}^{y}$ [see Fig. 4]. Consequently, we get new magnetic flux densities $\boldsymbol{B}_{\sigma}=\left\{B_{\sigma x} ; B_{\sigma y} ; B_{\sigma z}\right\}$ by considering the electrical conductivity.

\section{Result discussion}

In this section, all the results are calculated with $I_{\max }=7.78 \mathrm{~A}$ at $t=0 \mathrm{sec}$ and $h_{m p}=6 \mathrm{~mm}$ for two values of electrical frequency (viz., $50 \mathrm{~Hz}$ and 1,600 Hz). A very weak discretization has been imposed in the 3-D generic MEC obtaining a good approximation on the y-component of $\boldsymbol{B}$ in massive conductive parts. To improve the precision a high discretization can be applied on the 3-D generic MEC. The validation of proposed model has been realized on the Cedrat's Flux3D software package by using the application "Harmonic State 3-D" [11].

A 2-D view of the U-cored static electromagnetic device is illustrated in Figs. 4 for yz-plane [see Fig. 4(a)] and for xzplane [see Fig. 4(b)]. The 2-D grid $\mathrm{N}^{\circ} 1$ parallel to xz-plane and the 2-D grid $\mathrm{N}^{\circ} 2$ parallel to xy-plane are presented by the dashed black bold line for various comparisons.

Figs. 5 represent the evolution of the y-component of $\boldsymbol{B}$ on the 2-D grid $\mathrm{N}^{\circ} 1$ with(out) the skin effect. Fig. 5(a) corresponds to the magnetic flux density allowing to obtain the initial values of BCs (i.e., $H_{s}$ to estimate $M M F_{\sigma}^{m p}$ ). The results show a good agreement. Add to this, in Fig. 5(b), it can be clearly seen the deformation of the y-component of $\boldsymbol{B}_{\sigma}$ due to the electrical conductivity in massive conductive parts. Fig. 6(a) illustrates more clearly the impact of the massive conductive part on the behaviour of the magnetic field, where the skin effect appears slightly at $50 \mathrm{~Hz}$ contrary to $1,600 \mathrm{~Hz}$ that appears clearly as shown in Fig. 6(b). Indeed, the conductive massive part act as a barrier to the crossing flux. Using $\boldsymbol{J}=\boldsymbol{\nabla} \times \boldsymbol{H}_{\sigma}$ (i.e., Maxwell-Ampère), the absolute resultant current-density is shown in Fig. 7. Fig. 8 and Fig. 9 represent respectively the magnetic flux density map in term to components (i.e., $\mathrm{x}$ - and $\mathrm{y}$-component) on the 2-D grid $\mathrm{N}^{\circ} 2$ without and with the skin effect at $50 \mathrm{~Hz}$. From these figures, the influence of the existing massive conductive part can be seen, especially the magnetic flux density values that decrease in the most parts of the device, where the maximum value for $\mathrm{y}$-component go from $B_{y}=1 T$ to $B_{\sigma y}=0.8 T$ [see Fig. 8(a) and Fig. 9(a)] and from $B_{x}=0.8 T$ to $B_{\sigma x}=0.55 T$ [see Fig. 8(a) and Fig. 9(a)] for X-component. A particular attention can be given to $B_{\sigma x}$, in fact that it present a slight increase in the neighbouring region of the coil, where the X-component of magnetic flux density passes from $B_{x}=0.1 T$ to $B_{\sigma x}=0.2 T$. It can be noted that the massive conductive parts could affect the efficiency of the U-cored static electromagnetic device by increasing the flux leakage.

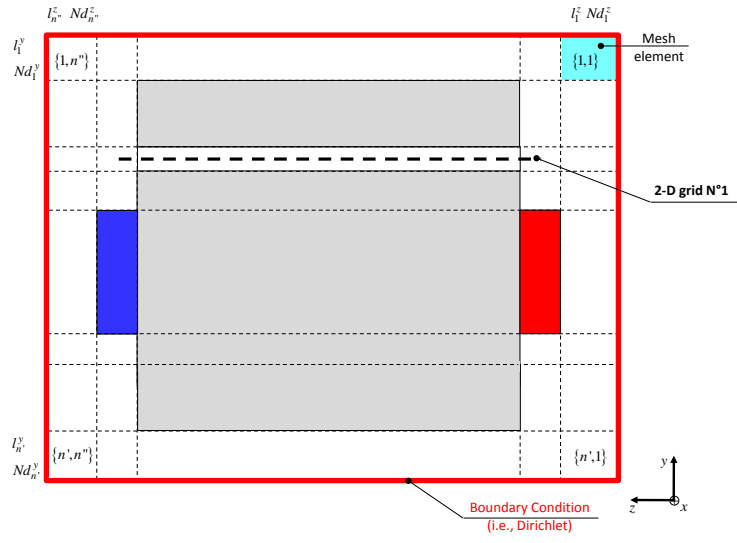

(a)

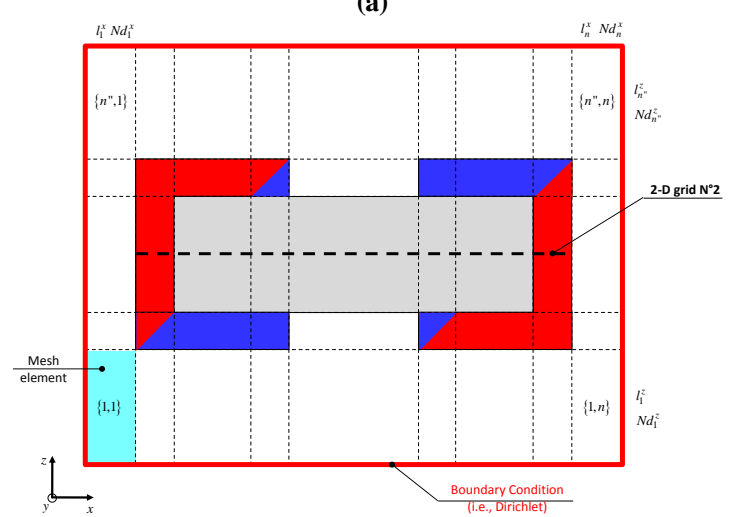

(b)

Fig. 4 2-D view of the U-cored static electromagnetic device in: (a) yz-plane, and (b) xz-plane.

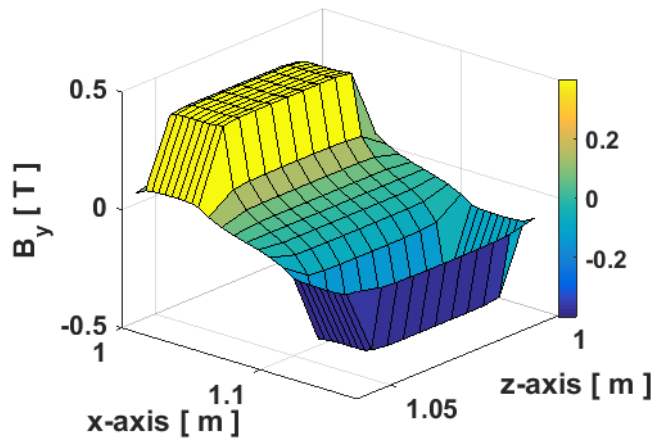

(a)

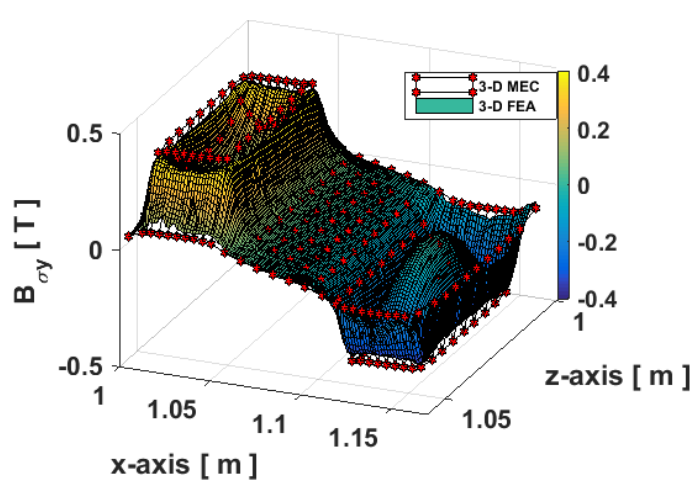

(b)

Fig. 5 The y-component of the magnetic flux density on the 2-D grid $\mathrm{N}^{\circ} 1$ : (a) without the skin effect, and (b) with the skin effect. 


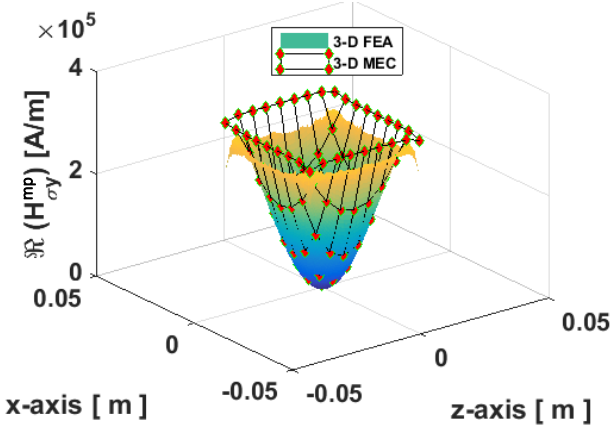

(a)

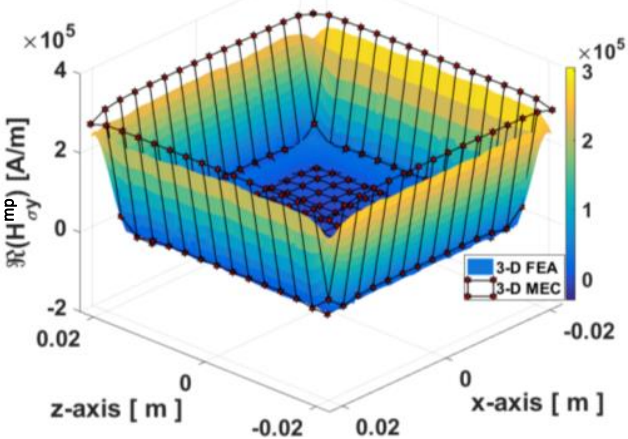

(b)

Fig. 6 Evolution of $H_{\sigma y}^{m p}$ in the massive conductive part for: (a) $f=50 \mathrm{~Hz}$, and (b) $f=1,600 \mathrm{~Hz}$.

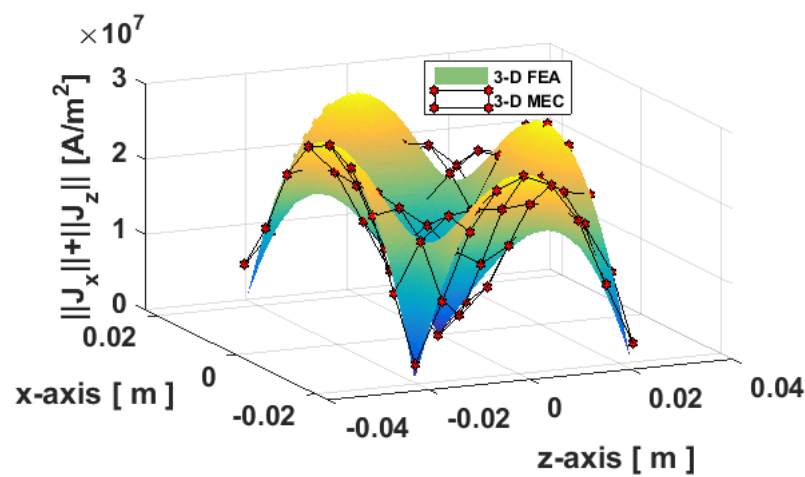

(a)

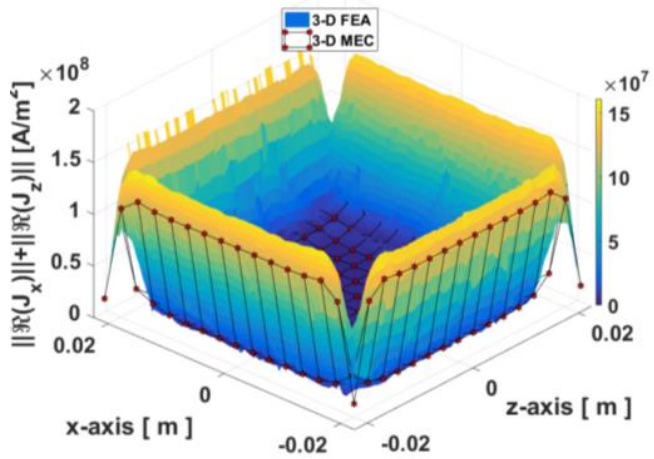

(b)

Fig. 7 Evolution of absolute $J$ in the massive conductive part for: (a) $f=50 \mathrm{~Hz}$, and (b) $f=1,600 \mathrm{~Hz}$.

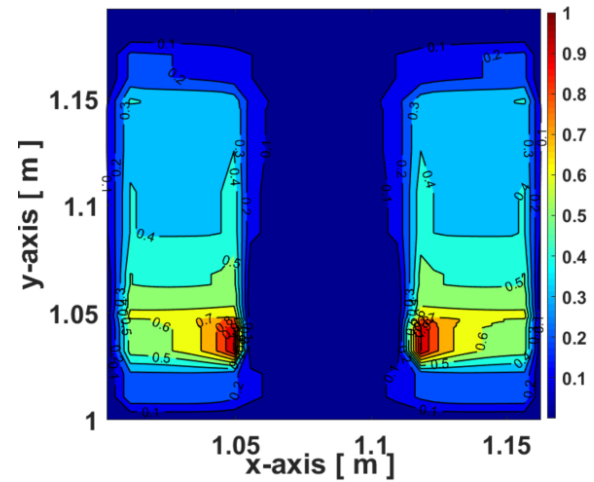

(a)

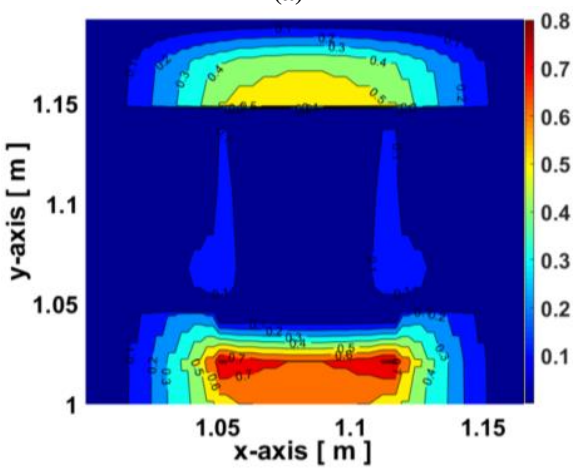

(b)

Fig. 8 Magnetic flux density map without the skin effect on the 2-D grid $\mathrm{N}^{\circ} 2$ for: (a) $B_{y}$, and (b) $B_{x}$

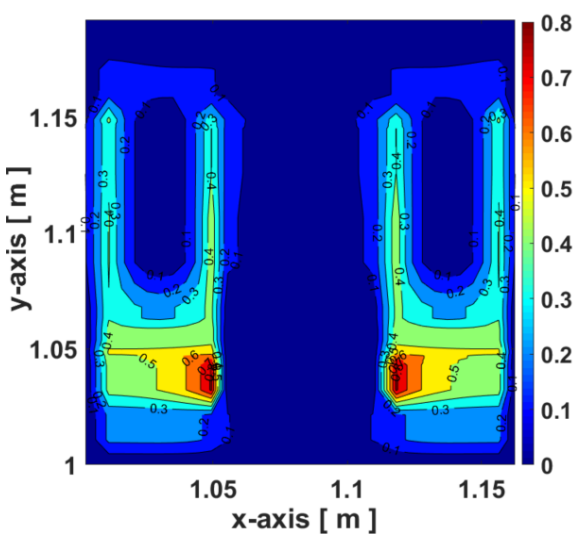

(a)

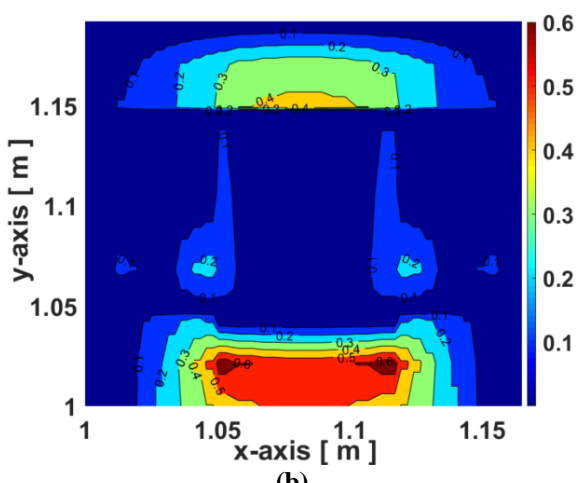

(b)

Fig. 9 Magnetic flux density map with the skin effect at $f=50 \mathrm{~Hz}$ on the 2$\mathrm{D}$ grid $\mathrm{N}^{\circ} 2$ for: (a) $B_{\sigma y}$, and (b) $B_{\sigma x}$. 


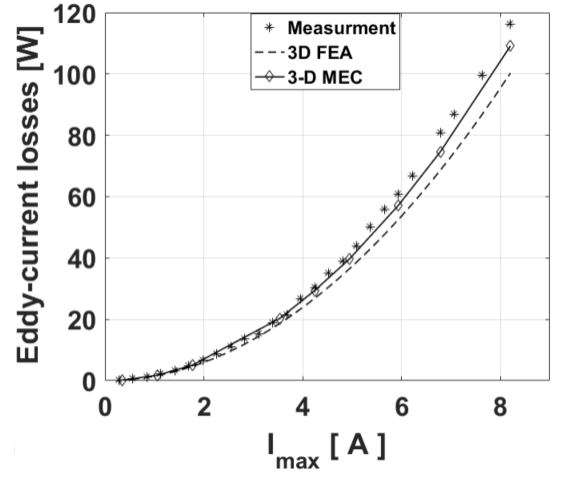

(a)

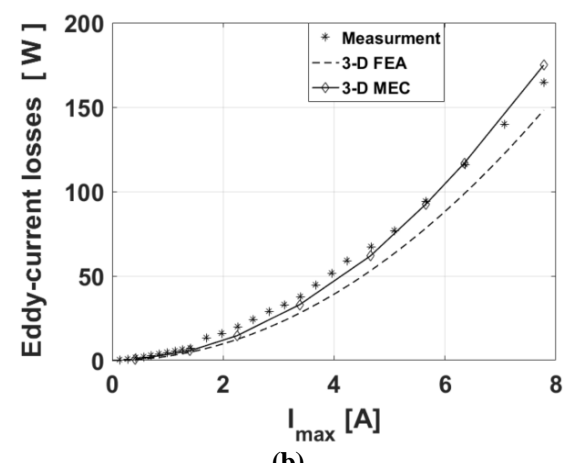

(b)

Fig. 10 Validation of eddy-current losses (3-D MEC, 3-D FEA and experimental) in conductive massive parts versus $I_{\max }$ at $f=50 \mathrm{~Hz}$ for: (a) $h_{m p}=6 \mathrm{~mm}$ and (b) $h_{m p}=10 \mathrm{~mm}$.

\section{Eddy-current loss calculation}

The 3-D eddy-current losses results given by the 3-D generic MEC with the skin effect are confronted with those obtained by 3-D FEA and experimental tests. For the experimental acquisition, these losses are calculated by using the separation of losses method [9]. In the proposed model, the eddy-current losses in the massive conductive part can be calculated by [1]

$$
W_{e d}=\frac{1}{\sigma_{m p}} \iiint_{V_{m p}}\left(J_{x}^{2}+J_{y}^{2}\right) \cdot d V
$$

where $V_{m p}$ is the volume of the massive conductive part.

The comparisons were performed at $50 \mathrm{~Hz}$ on two thickness in aluminium, viz., $6 \mathrm{~mm}$ and $10 \mathrm{~mm}$. Fig. 10 represent the evolution of $W_{e d}$ according to $I_{\max }$ [see Table 1]. The performed model gives a good agreement with both 3-D FEA and measurement.

\section{Conclusion}

In this work, a new approach is proposed to analyse the influence of the eddy-currents on the behaviour of the magnetic flux density over all the U-cored static electromagnetic devices. A 3-D generic MEC was used and improved taking into account skin effect in massive conductive parts. The classical MMF distribution has been modified by integrating the eddy-currents MMFs in massive conductive parts, which was introduced by a formula based on the Maxwell-Fourier method and by using the Hopkinson's law. It is able to compute the eddy-current losses in massive conductive parts. The model allows to study also the segmentation in both two space axes. Eddycurrent losses and local quantities resulted from 3-D generic MEC with the skin effect gives good agreement comparing to both measurement and 3-D FEA.

Acknowledgements This work was supported by RENAULT-SAS, Guyancourt France. This scientific study is related to the project "Conception optimale des chaines de Traction Electrique" (COCTEL) financed by the "Agence De l'Environnement et de la Maîtrise de l’Énergie” (ADEME).

\section{References}

1. R.L. Stoll, "The Analysis of Eddy Currents," Clarendon Press: Oxford, UK, 1974.

2. Z.Q. Zhu, K. Ng, N. Schofield, and D. Howe, "Improved Analytical Modeling of Rotor Eddy Current Loss in Brushless Machines Equipped with Surface Mounted Permanent Magnets", IEE Proc. Electr. Power Appl., vol. 151, no. 6, pp. 641-650, Nov. 2004.

3. R. Benlamine, F. Dubas, S.A. Randi, D. Lhotellier, and C. Espanet, "3-D Numerical Hybrid Method for PM EddyCurrent Losses Calculation: Application to axial-flux PMSMs", IEEE Trans. Magn., vol. 51, no. 7, Jul. 2015, Art. no. 8106110.

4. T. Gerlach, L. Rabenstein, A. Dietz, A. Kremser and D. Gerling "Determination of Eddy Current Losses in Permanent Magnets of SPMSM with Concentrated Windings: A Hybrid Loss Calculation Method and Experimental Verification", in Proc. EVER, Monte-Carlo, Monaco, Monaco, Apr. 10-12, 2018

5. H.Gholizad, B. Funieru, and A. Blinder, "Direct Modeling of Motional Eddy Currents in Highly Saturated Solid Conductors by the Magnetic Equivalent Circuit Method", IEEE Trans. Magn., vol. 45, no. 3, pp. 1016-1019, March 2009.

6. D. Bormann, and H. Tavakoli, "Reluctance Network Treatment of Skin and Proximity Effects in Multi-Conductor Transmission Lines", IEEE Trans. Magn., vol. 48, no. 2, pp. 735-738, Feb. 2012.

7. Y. Yoshida, K. Nakamura, and O. Ichinokura, "A Method for Calculating Eddy Current Loss Distribution Based on Electric and Magnetic Networks", IEEE Trans. Magn., vol. 47, no. 10, pp. 4155-4158, Oct. 2011.

8. Y. Yoshida, K. Nakamura, and O. Ichinokura, "Consideration of Eddy Current Loss Estimation in SPM Motor Based on Electric and Magnetic Networks", IEEE Trans. Magn., vol. 48, no. 11, pp. 3108-3111, Nov. 2012.

9. P.K. Chetangny, S. Houndedako, A. Vianou, and C. Espanet, "Eddy-current loss in a conductive material inserted into a Ucored electromagnetic device", in Proc. VPPC, Belfort, France, Dec. 11-14, 2017.

10. Y. Benmessaoud, F. Dubas, R. Benlamine, and M. Hilairet, "Three Dimensional Automatic Generation Magnetic Equivalent Circuit Using Mesh-Based Formulation", in Proc. ICEMS, Sydney, NSW, Australia, Aug. 11-14, 2017.

11. Flux2D/3D, "General operating instructions", Version 11.1., Cedrat S.A. Electrical Engineering, Grenoble, France, 2013. 